\title{
Phenolic compounds and antioxidant activity of berries produced in South Korea
}

\author{
Yongcheol Lee $^{1}$ (D) $\cdot$ Jea-Kyoo Lee ${ }^{1} \cdot$ Jeong-Gon Kim $^{1} \cdot$ So-Hyun Park $^{1} \cdot$ \\ Young-Eun Kim ${ }^{1} \cdot$ Sung-Kyu Park ${ }^{1} \cdot$ Moo-Sang Kim ${ }^{1}$
}

Received: 27 July 2020 / Accepted: 25 September 2020 / Published Online: 31 December 2020

(C) The Korean Society for Applied Biological Chemistry 2020

\begin{abstract}
Berries are rich sources of phenolic compounds, which are known to have health-promoting effects. In this study, phenolic compounds of seven popularly consumed berries were analyzed by HPLC-ESI-MS/MS. In addition, 2,2-diphenyl-1-picrylhydrazyl (DPPH) free radical and nitrite scavenging activities were investigated for comparison of the biological activity of the berry extracts. Chlorogenic acid was the major phenolic acid, which had the highest content in aronia, followed by blueberry. The rutin and isoquercetin contents were the highest in mulberry, followed by aronia, black raspberry, and blueberry. The anthocyanin content was the highest in black raspberry. Aronia showed the highest DPPH free radical and nitrite scavenging activities with the highest contents of total phenolics and proanthocyanidins.
\end{abstract}

Keywords Antioxidant activity - Aronia - Black raspberry · Blueberry $\cdot$ Mulberry $\cdot$ Phenolics

\section{Introduction}

Phenolic compounds constitute a large quantity of plant chemicals and are universally present in plants as secondary metabolites. They are divided into several types and are composed of a wide variety of compounds such as hydroxybenzoic acids, hydroxycinnamic

Yongcheol Lee $(\bowtie)$

E-mail: dreamykafka@gmail.com

${ }^{1}$ Seoul Metropolitan Government Research Institute of Public Health and Environment, Gwacheon-si 13818, Republic of Korea

This is an Open Access article distributed under the terms of the Creative Commons Attribution Non-Commercial License (http://creativecommons. org/licenses/by-nc/3.0/) which permits unrestricted non-commercial use, distribution, and reproduction in any medium, provided the original work is properly cited. acids, anthocyanins, proanthocyanidins, flavonols, flavones, and flavanols. Epidemiological evidence has suggested that the consumption of polyphenol-rich foods (fruits and vegetables) is associated with the prevention of diseases including cancer [1] and cardiovascular diseases [2]. In addition, previous epidemiological studies indicated that sufficient intake of phenolic compounds is closely related with reduction in the risk of chronic diseases $[3,4]$.

Berries are rich sources of phenolic compounds including anthocyanins, phenolic acids (PA), flavonoids, tannin, and organic acids, which are known to have health-promoting effects such as antioxidant activity, anti-inflammatory effect, and reduced risk of cancer and other chronic diseases [5-8]. Therefore, research interest and consumption of berries have been on a rise. In particular, small berries including aronia (black chokeberry, Aronia melanocarpa), mulberry (Morus alba), blueberry (Vaccinium corymbosum), black raspberry (Rubus coreanus), blackberry (Rubus fruticosus), raspberry (Rubus idaeus), and strawberry (Fragaria ananassa) are readily available in the market. Several studies have investigated the phenolic compounds and biological activity of berries. Moyer et al. [7] analyzed the anthocyanin and phenolics content in various small fruits (Vaccinium, Rubus, and Ribes) and investigated their antioxidant activity. Prior et al. [9] investigated the contents of total phenolics and anthocyanins and determined the antioxidant activity of some Vaccinium species. Some studies determined the phenolic compounds in aronia, blueberry, black raspberry, mulberry, and raspberry and revealed that phenolic compounds positively correlate with antioxidant activity [10-12]. However, studies that simultaneously investigate the phenolics content and antioxidant activity of small berries produced in Korea are limited.

In this study, therefore, phenolic compounds in seven popularly consumed berries were analyzed by LC-MS/MS. In addition, 2,2diphenyl-1-picrylhydrazyl (DPPH) free radical and nitrite scavenging activities were investigated for comparison of in vitro biological activity of the berry extracts. 


\section{Materials and Methods}

\section{Materials and chemicals}

Eleven samples of seven types of frozen berries produced in 2017 were purchased from local supermarkets: aronia (Muju, Jeonbuk), black raspberry (Jinan, Jeonbuk), blackberry, raspberry (Sangju, Gyeongbuk), strawberry (Cheongdo, Gyeongbuk), blueberry (Damyang, Jeonnam), and mulberry. All berries were domestic except one blueberry sample (blueberry-2, USA).

Methanol (Merck Chemicals, Darmstadt, Germany), ethanol (Fisher Scientific Korea Ltd., Seoul, Korea), hydrochloric acid (Matsunoen Chemicals Ltd., Osaka, Japan), and acetic acid (LCMS grade, Fisher Chemical Co., Leicestershire, UK) were purchased from various manufacturers. Folin-Ciocalteu reagent, sodium carbonate, potassium chloride, and naphthylethylenediamine dihydrochloride were procured from Wako Pure Chemical Industries (Osaka, Japan). Sodium acetate was purchased from Yakuri Pure Chemicals Co. (Kyoto, Japan). Phosphoric acid was obtained from Kanto Chemical Co. (Tokyo, Japan). Protocatechuic acid (PCA) was purchased from HWI Analytik GmbH (Ruelzheim, Germany). 4-Dimethylaminocinnamaldehyde (DMAC), chlorogenic acid (CGA), 4-hydroxybenzoic acid (4-HBA), ferulic acid, gallic acid, $p$-coumaric acid, $m$-coumaric acid, rutin, isoquercetin, taxifolin, scopoletin, morin, DPPH, 6-hydroxy-2,5,7,8-tetramethylchromane-2-carboxylic acid (Trolox), sodium nitrite, and sulphanilamide were purchased from Sigma-Aldrich Co. (St. Louis, MO, USA).

\section{Preparation of berry extracts}

Approximately 10-15 g of frozen fruits was mixed with $100 \mathrm{~mL}$ $80 \%(\mathrm{v} / \mathrm{v})$ ethanol $(0.1 \%$ hydrochloric acid) and then extracted with a homogenizer (OMNI Macro Homogenizer, OMNI International, Kennesaw, GA, USA) for $5 \mathrm{~min}$. The residue was re-extracted after centrifugation (SORVALL ST 16 centrifuge, Osterode am harz, Germany) at $3,000 \times \mathrm{g}$ for $5 \mathrm{~min}$, and the supernatant was collected. The collected extract was concentrated at $60{ }^{\circ} \mathrm{C}$ (Büchi Rotavapor and Heating Bath, Büchi, Flawil, Switzerland), and the residue was diluted to $50 \mathrm{~mL}$ with distilled water $(\mathrm{pH} 2.0)$, followed by filtration using a $0.2-\mu \mathrm{m}$ nylon filter (Chemco Scientific Co., Osaka, Japan). The extracts were stored at $-20{ }^{\circ} \mathrm{C}$ until analysis. The extracts were used for determination of phenolic compounds and antioxidant activity.

\section{Determination of total phenolics and anthocyanins}

The total phenolics content was determined by the Folin-Ciocalteu method [13]. A total of $0.1 \mathrm{~mL}$ of the extracts was mixed with $0.4 \mathrm{~mL}$ distilled water and $2.5 \mathrm{~mL} 0.2 \mathrm{~N}$ Folin-Ciocalteu reagent. After $5 \mathrm{~min}$ at room temperature, the mixture was reacted with $2 \mathrm{~mL} \mathrm{7.5 \% (w/v)} \mathrm{sodium} \mathrm{carbonate.} \mathrm{The} \mathrm{absorbance} \mathrm{was} \mathrm{measured}$ at $765 \mathrm{~nm}$ using a UV-Vis spectrophotometer (Agilent Technologies, Santa Clara, CA, USA) after $1 \mathrm{~h}$ at room temperature in the dark. The total phenolics content was expressed as mg gallic acid equivalents (eq)/100 $\mathrm{g}$ on fresh weight basis (FW).
The total anthocyanin content was measured using the AOAC $\mathrm{pH}$ differential method [14]. The extracts were diluted separately in volumetric flask with $\mathrm{pH} 1.0(0.025 \mathrm{M}$ potassium chloride $)$ and 4.5 ( $0.4 \mathrm{M}$ sodium acetate) buffers, and the absorbance was measured at 520 and $700 \mathrm{~nm}$ with the UV-Vis spectrophotometer. The total anthocyanin content was expressed as mg cyanidin 3glucoside eq/100 g FW with a cyanidin 3-glucoside molar extinction coefficient of 26,900 and a molecular weight of 449.2 .

\section{Determination of total proanthocyanidins}

The proanthocyanidin content was determined by the method of Prior et al. [15]. The extracts were mixed with $0.1 \%(\mathrm{w} / \mathrm{v})$ DMAC solution at room temperature for $10 \mathrm{~min}$; the absorbance was measured at $640 \mathrm{~nm}$ with the UV-Vis spectrophotometer. The proanthocyanidin content was expressed as $\mathrm{mg}$ catechin eq/100 g FW.

\section{HPLC-MS/MS analysis of nonanthocyanin phenolics}

The identification and quantification of nonanthocyanin phenolics were carried out by HPLC system (Agilent 1290 Infinity Series, Agilent Technologies) coupled with a 6495 triple quadrupole mass spectrometer (Agilent Technologies) equipped with an electrospray interface. The separation was conducted on an Atlantis T3 column ( $3 \mu \mathrm{m}, 2.1 \mathrm{~mm} \times 100 \mathrm{~mm}$; Waters Co., Milford, MA, USA) with a guard column (XDB C18, $5 \mu \mathrm{m}, 4.6 \mathrm{~mm} \times 12.5 \mathrm{~mm}$; Agilent Technologies) at $30{ }^{\circ} \mathrm{C}$. The mobile phase consisted of deionized water with $2 \%(\mathrm{v} / \mathrm{v})$ acetic acid (solvent A) and methanol (solvent B). The flow rate was $0.3 \mathrm{~mL} / \mathrm{min}$ with the following gradient elution program: $0-2 \mathrm{~min}, 5 \% \mathrm{~B} ; 2-7$ min linear gradient from 5 to $20 \% \mathrm{~B} ; 7-10 \min 20 \% \mathrm{~B} ; 10-13 \mathrm{~min}$ linear gradient from 20 to $30 \% \mathrm{~B}$; $13-15 \mathrm{~min} 30 \% \mathrm{~B}$; $15-18$ min linear gradient from 30 to $40 \% \mathrm{~B} ; 18-20 \mathrm{~min} 40 \% \mathrm{~B} ; 20-22$ min linear gradient from 40 to $50 \% \mathrm{~B} ; 22-24 \mathrm{~min} 50 \% \mathrm{~B}$; 24-28 min linear gradient from 50 to $95 \% \mathrm{~B} ; 28-30 \mathrm{~min} 95 \% \mathrm{~B} ; 30-31$ min linear gradient from 95 to $5 \% \mathrm{~B}$; and 4 min reconditioning. The injection volume was $2 \mu \mathrm{L}$ and detector wavelengths were 254, 280, and $360 \mathrm{~nm}$ (scan range: 200-600 nm). Mass spectroscopy was performed in a negative mode using multiple reaction monitoring under the optimal conditions. The optimum conditions were as follows: EM voltage, $-100 \mathrm{~V}$; cell accelerator voltage, $5 \mathrm{~V}$; fragmentor voltage, $380 \mathrm{~V}$; nitrogen gas flow, $15 \mathrm{~L} / \mathrm{min}$; gas temperature, $200{ }^{\circ} \mathrm{C}$; nebulizer pressure, $45 \mathrm{psi}$; sheath gas temperature, $350{ }^{\circ} \mathrm{C}$; sheath gas flow rate, $12 \mathrm{~L} / \mathrm{min}$; and capillary voltage, $-3000 \mathrm{~V}$. The Optimal conditions of LC-MS/MS for analysis of phenolic compounds are shown in Table 1. Reference materials (gallic acid, ferulic acid, 4HBA, PCA, CGA, $p$-coumaric acid, $m$-coumaric acid, isoquercetin, rutin, taxifolin, scopoletin, morin) were used for identification and quantification of nonanthocyanin phenolics.

\section{Determination of DPPH free radical scavenging activity}

The DPPH free radical scavenging activity was determined by the method of Brand-Williams et al. [16]. The diluted extracts $(0.1 \mathrm{~mL})$ 
Table 1 Optimal conditions of HPLC-MS/MS for analysis of phenolic compounds

\begin{tabular}{|c|c|c|c|c|c|}
\hline & Exact mass & Precursor ion $(\mathrm{m} / \mathrm{z})$ & Product ion $(\mathrm{m} / \mathrm{z})$ & $\mathrm{CE}$ & tR \\
\hline Gallic acid & 170.1 & 169 & 125 & -16 & 3.5 \\
\hline Ferulic acid & 194.2 & 193 & 134 & -15 & 17.9 \\
\hline 4-HBA & 138.1 & 137 & 93 & -12 & 9.4 \\
\hline Protocatechuic acid & 154.1 & 153 & 109 & -12 & 6.4 \\
\hline Chlorogenic acid & 354.3 & 353 & 191 & -18 & 10.7 \\
\hline$p$-Coumaric acid & 164.2 & 163 & 91 & -24 & 18.9 \\
\hline$m$-Coumaric acid & 164.2 & 163 & 119 & -8 & 16.3 \\
\hline Isoquercetin & 464.4 & 463 & 301 & -38 & 21.5 \\
\hline Rutin & 610.5 & 609 & 300 & -40 & 21.6 \\
\hline Taxifolin & 304.3 & 303 & 285 & -12 & 17.2 \\
\hline Scopoletin & 192.2 & 191 & 176 & -14 & 16.5 \\
\hline Morin & 302.2 & 301 & 151 & -28 & 24.5 \\
\hline
\end{tabular}

4-HBA, 4-hydroxybenzoic acid; CE, collision energy; tR, peak retention time

were reacted with $3.9 \mathrm{~mL} 0.1 \mathrm{mM}$ DPPH methanolic solution. After $30 \mathrm{~min}$ of reaction, the absorbance was measured at $517 \mathrm{~nm}$ with the UV-Vis spectrophotometer. The DPPH free radical scavenging activity was expressed as the trolox equivalent antioxidant capacity (TEAC, $\mu \mathrm{mol} / 100 \mathrm{~g} \mathrm{FW})$.

\section{Determination of nitrite scavenging activity}

The nitrite scavenging activity was determined using the method of Kato et al. [17] and Kang et al. [18]. The extracts $(0.2 \mathrm{~mL})$ were mixed with $1 \mathrm{~mL}$ of $1 \mathrm{mM}$ sodium nitrite solution, and the mixed solution was adjusted to $\mathrm{pH} 1.2$ (using $0.1 \mathrm{M}$ hydrochloric acid), followed by incubation for $1 \mathrm{~h}$. Next, $1 \mathrm{~mL}$ of the sample

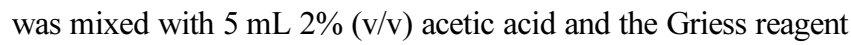
$(1 \%(\mathrm{w} / \mathrm{v})$ sulphanilamide with $5 \%$ phosphoric acid and $0.1 \%$ (w/v) naphthylethylenediamine dihydrochloride). After $15 \mathrm{~min}$ of reaction, the absorbance was measured at $520 \mathrm{~nm}$ using the UVVis spectrophotometer. The nitrite scavenging activity was expressed as the ratio of the absorbance of the blank (distilled water) and samples:

Nitrite scavenging ability $(\%)=(1-(\mathrm{A}-\mathrm{C}) / \mathrm{B}) \times 100$,

where $\mathrm{A}$ is the absorbance of the samples with the Griess reagent, $\mathrm{B}$ is the absorbance of the blank (distilled water) with the Griess reagent, and $\mathrm{C}$ is the absorbance of the samples without the Griess reagent.

\section{Statistical analysis}

All experiments were performed in triplicate and data were expressed as means \pm standard deviations. To compare differences among the data, statistical analysis was performed using the SPSS program (SPSS version 20.0) and the data analyzed by analysis of variance (ANOVA). After the ANOVA analysis, significant differences were determined with Duncan's multiple range test at $p<0.05$. Correlation analysis was performed among total phenolics, anthocyanins, proanthocyanidins, DPPH, and nitrite scavenging activity. The strength of the correlation relationship was determined by Pearson correlation coefficient $r$ and p-level.

\section{Results and Discussion}

Total phenolics, anthocyanins, and proanthocyanidins of berries The total phenolic and anthocyanin contents of the berries are shown in Fig. 1. Aronia contained $(p<0.05)$ the highest total phenolics content ( $833.5 \mathrm{mg} / 100 \mathrm{~g} \mathrm{FW})$, followed by black raspberry (573.3) and mulberry (550.9). The total phenolics content of the other berries ranged from 92.0 to 231.1. On the other hand, total anthocyanins were the most abundant in black raspberry (421.0 $\mathrm{mg} / 100 \mathrm{~g} \mathrm{FW}$ ), followed by mulberry (359.3), aronia (259.2), and blueberry (179.4). These results were similar to those of previous studies: the total phenolics content of aronia was higher than that of blueberry [10], and the total phenolics and anthocyanin contents of 10 Highbush blueberry cultivars ranged from 181.1 to 390.5 and from 92.6 to 235.4, respectively [9]. Lee at al. [12] reported that the total phenolics (547.2) and anthocyanin (385.6) contents of black raspberry were higher than those of mulberry (331.6 and 118.9), blueberry (298.2 and 165.0), and raspberry (198.2 and 19.8).

Proanthocyanidins are powerful antioxidants, with the potential to prevent cardiovascular disease, cancers, and Alzheimer's disease [19]. As shown in Fig. 2, the proanthocyanidin content of aronia $(97.8 \mathrm{mg} / 100 \mathrm{~g} \mathrm{FW})$ was five times higher than that of the other berries (3.2-16.6). Aronia had higher total phenolic and proanthocyanidin contents than black and red currants, gooseberry, and elderberry [20]. Therefore, aronia is determined to be rich in phenolics and proanthocyanidins and might exhibit higher antioxidant activity than the other berries.

\section{Phenolic compounds in berries}

The total ion chromatograms and the contents of phenolic 

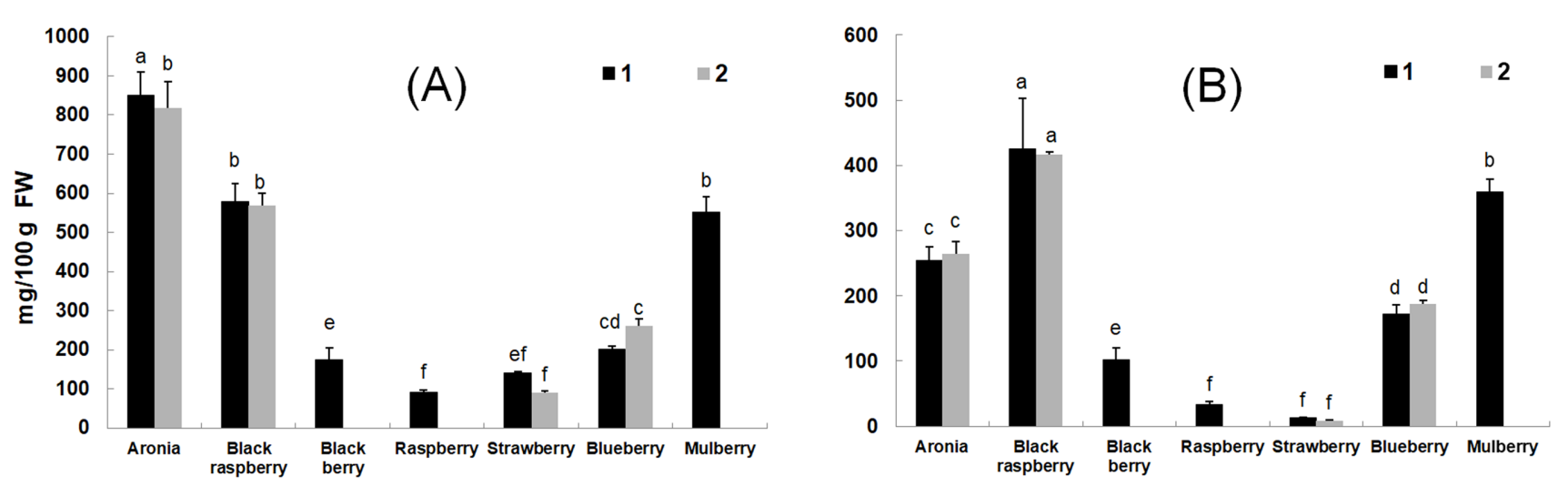

Fig. 1 Total phenolics (A) and anthocyanins (B) in the seven types of berries. FW, Fresh weight basis; Total phenolics are expressed as mg gallic acid equivalent per $100 \mathrm{~g} \mathrm{FW}$. Total anthocyanins are expressed as mg anthocyanin 3-glucoside equivalent per $100 \mathrm{~g}$ FW. Bars represent means \pm standard deviations $(n=3)$. Different letters $(a-f)$ above the bars in the groups of total phenolics and anthocyanins indicate significantly different by Duncan's multiple range test at $p<0.05$

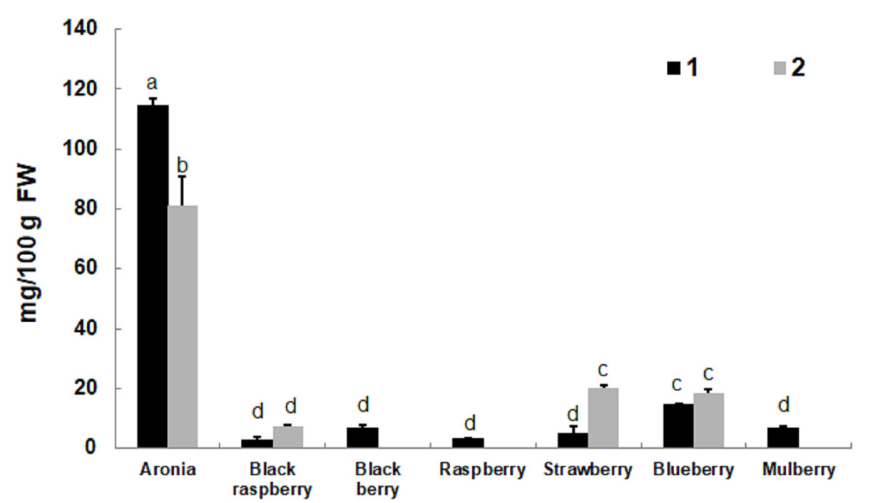

Fig. 2 Total proanthocyanidins in the seven types of berries. FW, Fresh weight basis; Total proanthocyanidins are expressed as mg catechin equivalent per $100 \mathrm{~g}$ FW. Bars represent means \pm standard deviations $(n=3)$. Different letters (a-d) above the bars in the groups of Total proanthocyanidins indicate significantly different by Duncan's multiple range test at $p<0.05$

compounds analyzed using LC-MS/MS are shown in Fig. 3 and Table 2. The major phenolic compounds contained in the berries were CGA, PCA, 4-HBA, rutin, and isoquercetin. Other compounds ( $p$-coumaric acid, $m$-coumaric acid, taxifolin, scopoletin, and morin) were not listed in Table 2, since they were not detected or trace amounts in the berries. The content of 4-HBA was 0.4-2.8 $\mathrm{mg} / \mathrm{kg} \mathrm{FW}$ and was the highest in raspberry. PCA was not detected in strawberry, blackberry, and blueberry; however, aronia had the highest content of PCA among the berries. CGA constituted the largest content of PAs in the berries. Among the berries, aronia (253.4 mg/kg FW) contained the highest CGA content, followed by blueberry (214.0) and mulberry (36.0), whereas the lowest levels were found in the berries of Rubus species, which corroborated with the results of Lee et al. [12] indicating that CGA was not detected in black raspberries. As an inhibitor of glucose-6-phosphatase, CGA reduces the rate of the hepatic release of glucose, resulting in decline in blood glucose levels
[21]. Bassoli et al. [22] observed that CGA inhibited glucose-6phosphatase capacity on the microsome fraction of rat liver and decreased the glucose transport ability of brush-border membrane vesicles isolated from the small intestine of rat. Therefore, aronia, blueberry, and mulberry containing abundant CGA may exhibit hypoglycemic effects.

Two major flavonols, rutin and isoquercetin contents of the berries are listed in Table 2. Mulberry had the highest rutin content (205.8 mg/kg FW), followed by black raspberry (65.4), aronia (50.3), blackberry (8.6), and blueberry (7.3), whereas rutin was not detectable in raspberry and strawberry. The average isoquercetin content in blueberry was $34.6 \mathrm{mg} / \mathrm{kg} \mathrm{FW}$, which was higher than that in aronia (22.4). The isoquercetin content in the other berries ranged from 1.2 to $8.1 \mathrm{mg} / \mathrm{kg} \mathrm{FW}$. The content of total quercetins (rutin and isoquercetin) was the highest in mulberry, whereas that in strawberry was not detectable. These results agreed with those reported by Lee et al. [12], who determined that the quercetin content of raspberry was the lowest among four berries (black raspberry, mulberry, blueberry, and raspberry). On the other hand, they revealed that quercetins were more abundant in black raspberry than in mulberry and blueberry, which was inconsistent with our result [12]. It has been suggested that the differences of the phenolic contents in berries are known to depend on a number of factors, including maturity, genetic diversity, and environmental conditions [7,23,24]. Flavonols are the flavonoid that is most widely distributed in plant bodies, mostly in the form of glycoside [25]: fruits and vegetables contain high content of quercetins [26]. Son and Choi [27] reported that among the four berries (mulberry, black raspberry, blueberry, and raspberry), mulberry wine containing abundant quercetins and derivatives showed the highest $\alpha$ glucosidase inhibition, indicating that mulberry rich in rutin and isoquercetin might exhibit an $\alpha$-glucosidase inhibitory effect.

DPPH radical and nitrite scavenging activities of berries Phenolic compounds abundantly present in plants, including 


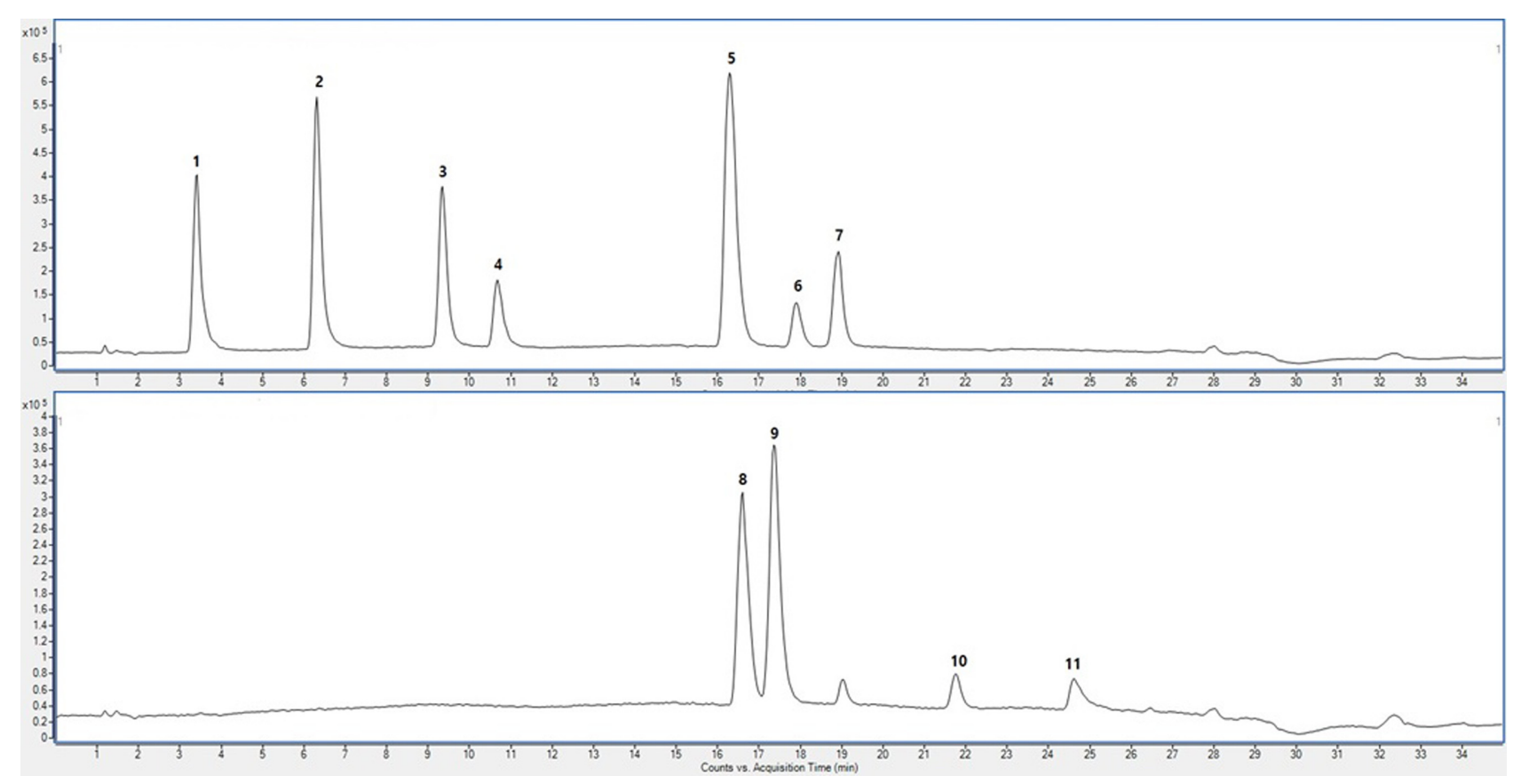

Fig. 3 Total ion chromatograms of phenolics standard mixtures. 1, gallic acid; 2, protocatechuic acid; 3, 4-hydroxybenzoic acid; 4, chlorogenic acid; 5, $m$-coumaric acid; 6 , ferulic acid; 7, $p$-coumaric acid; 8 , scopoletin; 9, taxifolin; 10, isoquercetin/rutin; 11, morin

Table 2 Contents of major phenolic compounds in the seven types of berries ( $\mathrm{mg} / \mathrm{kg}$ on fresh weight basis)

\begin{tabular}{|c|c|c|c|c|c|c|c|c|c|}
\hline & \multicolumn{6}{|c|}{ Phenolic acids } & \multicolumn{3}{|c|}{ Quercetins } \\
\hline & GA & FA & 4-HBA & PCA & CGA & Total & IQC & Rutin & Total \\
\hline Aronia-1 & $\operatorname{Tr}$ & $0.3 \mathrm{bc}$ & $0.5 \mathrm{c}$ & $8.2 \mathrm{ab}$ & $266.3 \mathrm{a}$ & $275.3 \mathrm{a}$ & $23.7 \mathrm{~b}$ & $52.0 \mathrm{c}$ & $75.7 \mathrm{bc}$ \\
\hline Aronia-2 & $\operatorname{Tr}$ & $0.2 \mathrm{c}$ & $0.9 \mathrm{c}$ & $8.8 \mathrm{a}$ & $240.6 \mathrm{a}$ & $250.5 \mathrm{a}$ & $21.1 \mathrm{~b}$ & $48.5 \mathrm{c}$ & $69.6 \mathrm{bcd}$ \\
\hline Black raspberry-1 & $0.9 \mathrm{abc}$ & $0.3 \mathrm{bc}$ & $1.5 \mathrm{~b}$ & $8.1 \mathrm{ab}$ & $\operatorname{Tr}$ & $10.9 \mathrm{~d}$ & $3.7 \mathrm{de}$ & $54.0 \mathrm{c}$ & $57.7 \mathrm{~d}$ \\
\hline Black raspberry-2 & $1.3 \mathrm{ab}$ & $0.2 \mathrm{c}$ & $1.0 \mathrm{bc}$ & $7.6 \mathrm{ab}$ & $0.2 \mathrm{c}$ & $10.3 \mathrm{~d}$ & $3.5 \mathrm{de}$ & $76.8 \mathrm{~b}$ & $80.2 \mathrm{~b}$ \\
\hline Blackberry & $0.2 \mathrm{~cd}$ & $0.5 \mathrm{~b}$ & $0.9 \mathrm{c}$ & $1.2 \mathrm{~cd}$ & nd & $2.7 \mathrm{~d}$ & $3.2 \mathrm{de}$ & $8.6 \mathrm{~d}$ & $11.7 \mathrm{ef}$ \\
\hline Raspberry & $\operatorname{Tr}$ & $0.3 \mathrm{bc}$ & $3.0 \mathrm{a}$ & $4.0 \mathrm{bcd}$ & nd & $7.3 \mathrm{~d}$ & $1.2 \mathrm{e}$ & nd & $1.2 \mathrm{f}$ \\
\hline Strawberry-1 & $1.1 \mathrm{ab}$ & $0.3 \mathrm{bc}$ & $0.5 \mathrm{c}$ & $\operatorname{Tr}$ & nd & $1.9 \mathrm{~d}$ & nd & nd & - \\
\hline Strawberry-2 & $\operatorname{Tr}$ & $0.1 \mathrm{c}$ & $0.6 \mathrm{c}$ & $\operatorname{Tr}$ & nd & $0.7 \mathrm{~d}$ & nd & nd & - \\
\hline Blueberry-1 & $0.9 \mathrm{abc}$ & $0.3 \mathrm{bc}$ & nd & $\operatorname{Tr}$ & $253.3 \mathrm{a}$ & $254.5 \mathrm{a}$ & $10.9 \mathrm{c}$ & $11.9 \mathrm{~d}$ & $22.8 \mathrm{e}$ \\
\hline Blueberry-2 & $0.5 \mathrm{bcd}$ & $0.8 \mathrm{a}$ & nd & $0.2 \mathrm{~d}$ & $174.7 \mathrm{~b}$ & $176.2 \mathrm{~b}$ & $58.3 \mathrm{a}$ & $2.7 \mathrm{~d}$ & $60.9 \mathrm{~cd}$ \\
\hline Mulberry & $\operatorname{Tr}$ & $0.1 \mathrm{c}$ & $0.9 \mathrm{c}$ & $5.1 \mathrm{abc}$ & $36.0 \mathrm{c}$ & $42.0 \mathrm{c}$ & $8.1 \mathrm{~cd}$ & $205.8 \mathrm{a}$ & $214.0 \mathrm{a}$ \\
\hline
\end{tabular}

GA, gallic acid; FA, ferulic acid; 4-HBA, 4-hydroxybenzoic acid; PCA, protocatechuic acid; CGA, chlorogenic acid; IQC, isoquercetin; Tr, trace $(<0.1)$; nd, not detected; Values are means $(\mathrm{n}=3)$; Values with different lower case letters within the same column are significantly different by Duncan's multiple range test at $p<0.05$

fruits, are known to be closely correlated to promoting the elimination of reactive oxygen species. The health-promoting effect of plant and fruits for prevention of chronic diseases can be partly attributed to the antioxidant activity of phenolic compounds. The antioxidant activity of the berries was determined as a scavenging effect toward the DPPH free radical cation. As shown in Fig. 4A, the DPPH scavenging activity of the berries was 5.441.2 TEAC $\mu \mathrm{mol} / 100 \mathrm{~g}$ FW. Aronia (41.2), black raspberry (32.8), and mulberry (20.7) exhibited DPPH scavenging activity 2.5-fold higher than blueberry (7.7), blackberry (7.0), strawberry (5.6), and raspberry (5.4). A similar result exhibited that aronia showed the highest antioxidant activity, identical to DPPH, and ABTS radical scavenging activities [10] and ORAC [20] among berry species. Moreover, Posedek et al. [28] reported that aronia exhibited the highest antioxidant activity (ABTS and FRAP assay) among 30 commonly consumed fruits including nine berry species.

Green leafy vegetables, including spinach, are a rich source of nitrate in the diet. Sodium nitrate is generally applied for meat curing to prevent bacterial growth and give a desirable pink-red "fresh" color. Consumption of large amounts of food containing high levels of nitrate could cause methemoglobinemia. Additionally, 

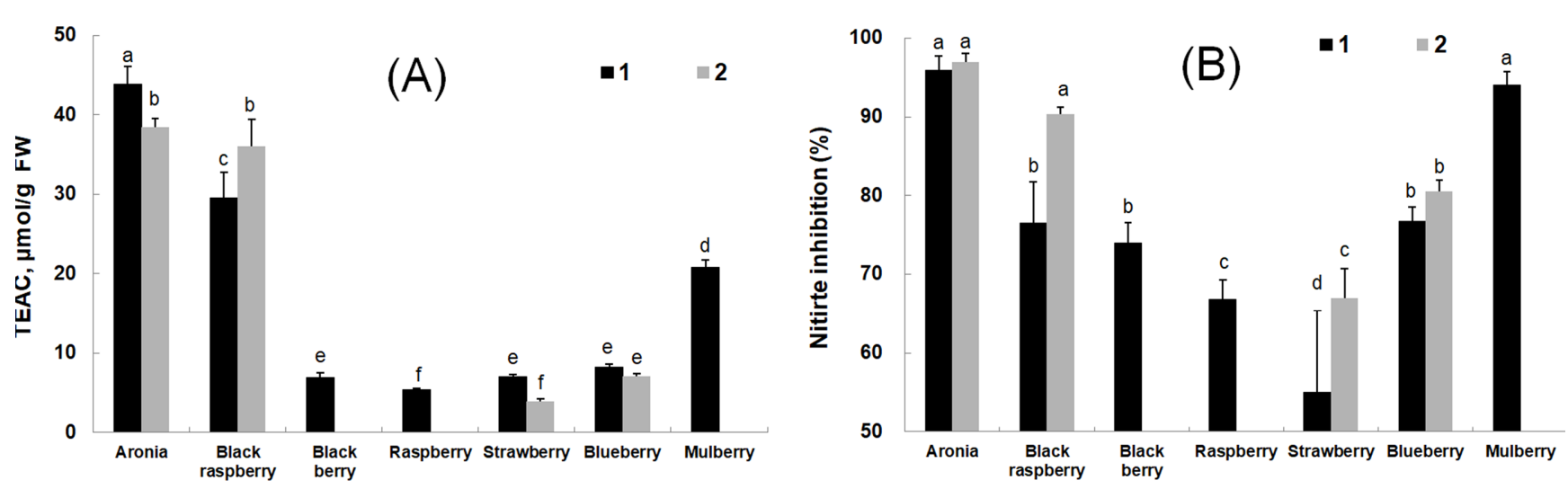

Fig. 4 DPPH free radical (A) and nitrite (B) scavenging activities of the seven types of berries. FW, Fresh weight basis; TEAC, trolox quivalent antioxidant capacity; Bars represent means \pm standard deviations $(n=3)$. Different letters (a-f) above the bars in the groups of DPPH free radical and nitrite scavenging activity indicate significantly different by Duncan's multiple range test at $p<0.05$

Table 3 Pearson correlation coefficient $(r)$ between phenolic compounds and DPPH free radical and nitrite scavenging activities of the seven types of berries

\begin{tabular}{lcc}
\hline \hline & $\begin{array}{c}\text { DPPH radical } \\
\text { scavenging activity }\end{array}$ & $\begin{array}{c}\text { Nitrite } \\
\text { scavenging activity }\end{array}$ \\
\hline Total phenolics & $0.969^{* *}$ & $0.864^{* *}$ \\
Total anthocyanins & $0.754^{* *}$ & $0.742^{* *}$ \\
Total proanthocyanidins & $0.664^{*}$ & - \\
\hline
\end{tabular}

**, significantly at $p<0.01$ level; $*$, significantly at $p<0.05$ level

nitrite could undergo nitrosation to convert to nitrosamines, which are carcinogens. It is well known that nitrosamine generation can be inhibited by reducing agents such as ascorbate, phenolic compounds, and phenolics-rich compounds [18,29,30]. Figure 4B shows the nitrite scavenging activity of the berries. Aronia $(96.4 \%)$, mulberry (94.1\%), and black raspberry (83.4\%) exhibited higher nitrite scavenging activity than other berries (61.0-78.6\%). Chung [11] observed a similar trend in that the methanolic extract of aronia has the highest effect of nitrite inhibition among other berries. These results suggested that phenolic compounds could inhibit nitrosamine formation by reducing nitrite to nitrogen oxide. As shown in Table 3, the DPPH radical scavenging activity was positively correlated to total phenolics $(r=0.969, p<0.01)$ and anthocyanins $(r=0.864, p<0.01)$. The nitrite scavenging activity was also positively correlated to total phenolics $(r=0.754, p<0.01)$ and anthocyanins $(r=0.742, p<0.01)$. Correlation coefficient $r$ between DPPH free radical and total proanthocyanins was 0.664 $(p<0.05)$. Previous studies demonstrated the correlation between antioxidant activity and phenolic compounds. Lee at al. [12] revealed the positive correlation $(r>0.85, p<0.01)$ between total phenolics and anthocyanins and antioxidant activity (DPPH and ABTS radical scavenging activities) in four berries. Jung [10] reported that total phenolics and flavonoids were highly correlated to antioxidant activity in aronia and blueberry. Moreover, total phenolics were positively correlated $(r>0.82)$ with the ORAC value and DPPH free radical scavenging activity in raspberry. In addition, total phenolics were more highly correlated to antioxidant activity (ORAC and FRAP assay) than total anthocyanins [7]. These results indicated that phenolic compounds may be the main contributor to antioxidant activity.

Conflict of interest This research did not receive any specific grant from funding agencies in the public, commercial, or not-for-profit sectors.

\section{References}

1. Steinmetz KA, Potter JD (1996) Vegetables, fruit, and, cancer prevention: a review. J Am Diet Assoc 96: 1027-1039

2. Ness AR, Powles JW (1997) Fruit and vegetables and cardiovascular disease: a review. Int J Epidemiol 26: 1-13

3. Arts ICW, Hollman PCH (2005) Polyphenols and disease risk in epidemiologic studies. Am J Clin Nutr 81(Suppl): 317S-325S

4. Tomas-Barberan FA, Andres-Lacueva C (2012) Polyphenols and health: current state and progress. J Agric Food Chem 60: 8773-8775

5. Badjakov I, Nikolova M, Gevrenova R, Kondakova V, Todorovska E, Atanassov A (2008) Bioactive compounds in small fruits and their influence on human health. Biotechnolo Biotec EQ 22: 581-587

6. Bagchi D, Sen CK, Bagchi M, Atalay M (2004) Anti-angiogenic, antioxidant, and anti-carcinogenic properties of a novel anthocyanin-rich berry extract formula. Biochemistry (Moscow) 69: 75-80

7. Moyer RA, Hummer KE, Finn CE, Frei B, Wrolstad RE (2002) Anthocyanins, phenolics, and antioxidant capacity in diverse small fruits: Vaccinium, Rubus, and Ribes. J Agric Food Chem 50: 519-525

8. Seeram NP, Adams LS, Zhang Y, Lee R, Henry DS, Scheuller HS, Heber D (2006) Blackberry, black raspberry, blueberry, cranberry, red raspberry, and strawberry extracts inhibit growth and stimulate apoptosis of human cancer cells in vitro. J Agric Food Chem 54: 9329-9339

9. Prior RL, Wu X (2006) Anthocyanins: Structural characteristics that result in unique metabolic patterns and biological activities. Free Radic Res 40: 1014-1028

10. Chung HJ (2014) Comparison of total polyphenols, total flavonoids, and biological activities of black chokeberry and blueberry cultivated in Korea. J Korean Soc Food Sci Nutr 43: 1349-1356

11. Chung HJ (2016) Comparison of bioactive constituents and biological 
activities of aronia, blackcurrant and maquiberry. J Korean Soc Food Sci Nutr 45: 1122-1129

12. Lee YC, Lee JH, Kim SD, Chang MS, Jo IS, Kim SJ, Hwang KT, Jo $\mathrm{HB}$, Kim JH (2015) Chemical composition, functional constituents, and antioxidant activities of berry fruits produced in Korea. J Korean Soc Food Sci Nutr 44: 1295-1303

13. Singleton VL, Orthofer R, Lamuela-Raventos RM (1999) Analysis of total phenols and other oxidation substrate and antioxidants by means of Folin-Ciocalteu reagent. Methods Enzymol 299: 152-178

14. AOAC (2005) Official methods of analysis (18th ed). Gaithersburg, MD, USA: Association of official analytical chemist

15. Prior RL, Fan E, Ji H, Howell A, Nio C, Payne MJ, Reed J (2010) Multi-laboratory validation of a standard method for quantifying proanthocyanidins in cranberry powders. J Sci Food Agric 90: 14731478

16. Brand-Williams W, Cuvelier ME, Berset C (1995) Use of a free radical method to evaluate antioxidant activity. Food Sci Technol 28: 25-30

17. Kato H, Lee IE, Chuyen NV, Kim SB, Hayase F (1987) Inhibition of Nitrosamine formation by nondialyzable melanoidins. Agr Biol Chem 51: $1333-1338$

18. Kang YH, Park YK, Lee GD (1996) The nitrite scavenging and electron donating ability of phenolic compounds. Korean J Food Sci Technol 28: 232-239

19. Sharma V, Zhang C, Pasinetti GM, Dixon RA (2011) Fractionation of Grape Seed Proanthocyanidins for Bioactivity Assessment. In Gang, D. (Eds.) The Biological Activity of Phytochemicals. Recent Advances in Phytochemistry, 41. Springer, New York, NY

20. Wu X, Gu L, Prior RL, McKay S (2004) Characterization of anthocyanins and proanthocyanidins in some cultivars of Ribes, Aronia, and Sambucus and their antioxidant capacity. J Agric Food Chem 52: 7846-7856

21. Schindler PW, Below P, Hemmerle H, Burger HJ, Swamy KHS, Arion
WJ, Efendic S, Herling AW (1998) Identification of two new inhibitors of the hepatic glucose-6-phosphate system. Drug Develop Res 44: 34-40

22. Bassoli BK, Cassolla P, Borda-Murad GR, Constantin J, SalgueiroPagadigorria CL, Bazotte RB, Silva RSSF, Souza HM (2008) Chlorogenic acid reduces the plasma glucose peak in the oral glucose tolerance test: effects on hepatic glucose release and glycaemia. Cell Biochem Funct 26: 320-328

23. Pawlowska AM, Oleszek W, Braca A (2008) Quali-quantitative analyses of flavonoids of Morus nigra L. and Morus alba L. (Moraceae) fruits. J Agric Food Chem 56: 3377-3380

24. Zadernowski R, Naczk M, Nesterowicz J (2005) Phenolic acid profiles in some small berries. J Agric Food Chem 53: 2118-2124

25. Mullen W, Boitier A, Stewart AJ, Crozier A (2004) Flavonoid metabolites in human plasma and urine after the consumption of red onions: Analysis by liquid chromatography with photodiode array and full scan tandem mass spectrometric detection. J Chromatogr A 1058: 163-168

26. Marks SC, Mullen W, Crozier A (2007) Flavonoid and chlorogenic acid profiles of English cider apples. J Sci Food Agric 87: 719-728

27. Son WR, Choi SW (2013) Biological activity and analysis of $\alpha$ glucosidase inhibitor from mulberry (Morus alba L.) wine. Korean J Food Preserv 20: 877-885

28. Podsedek A, Majewska I, Redzynia M, Sosnowska D, Koziolkiewicz M (2014) In vitro inhibitory effect on digestive enzymes and antioxidant potential of commonly consumed fruits. J Agric Food Chem 62: 4610 4617

29. Chung SY, Kim NK, Yoon S (1999) Nitrite scavenging effect of methanol fraction obtained from green yellow vegetable juices. J Korean Soc Food Sci Nutr 28: 342-347

30. Mirvish SS, Wallcave L, Eagen M, Shubik P (1972) Ascorvate-nitrite reaction: possible means of blocking the formation of carcinogenic $\mathrm{N}$ nitroso compounds. Science 177: 65-68 